\title{
Research on the impact of R\&D investment on the international competitiveness of communication and electronic equipment industry in Hubei Province
}

\author{
Yiwei Wang ${ }^{1 *}$ and Zipeng $\mathrm{Yu}^{2}$ \\ ${ }^{1}$ Wuhan University of Science and Technology Wu Han, China \\ ${ }^{2}$ Wuhan University of Science and Technology Wu Han, China
}

\begin{abstract}
R\&D investment has always been one of the most active factors in the economic development of China's manufacturing industry. Therefore, this paper analyzes the communication and electronic equipment industry in Hubei Province from all aspects of R\&D investment, explores the competitive advantages in the development process of the industry, and looks for the future development direction of the industry in Hubei Province, so as to better complete the transformation and upgrading of the industry. Based on the current international competitiveness evaluation index system, the research on the development status of the communication and electronic equipment industry can be analyzed from the perspective of industrial international competitiveness. The industrial R\&D investment is divided into three parts: personnel, capital and efficiency. R\&D personnel investment and R\&D capital investment have a positive impact on the international competitiveness of the industry, and R\&D input-output efficiency has a positive impact on the international competitiveness of the industry There is a slight negative effect. It is pointed out that the future development direction of Hubei electronic technology industry in R\&D investment should focus on personnel investment and capital investment.
\end{abstract}

\section{Introduction and literature review}

According to the manufacturing power development index of various countries since 2012 published in the 2020 China manufacturing power development index report, the development of China's manufacturing industry is still in the third echelon, with a comparative advantage. According to the $R \& D$ census communique released by the National Bureau of statistics, the national R\&D investment in 2018 was 1967.79 billion yuan, with a growth rate of $11.8 \%$. Under the situation of continuous increase of $R \& D$ investment, this paper analyzes how R\&D investment affects the development of equipment manufacturing industry, and analyzes it according to the existing international competitiveness index system. At the Fifth Plenary Session of the 19th CPC Central Committee held in October, it was pointed out that innovation is at the core of China's modern economic construction by persisting in the development of the real economy and building a powerful manufacturing country. We should continue to implement the innovation driven development strategy, adhere to the double cycle development with internal circulation as the main part, and make deep independent innovation to better promote the upgrading of the industrial structure. The central working conference held in December also pointed out that we should strengthen the strength of science and technology and comprehensively promote reform and opening up. How does R\&D investment, as a positive factor of technological progress, affect industrial development and enhance its international competitiveness? This paper analyzes the $R \& D$ investment structure of the equipment manufacturing industry, reveals the possible problems in the development, and puts forward the adjustment countermeasures for the problems.

Youwei Zhu (2006) used the parametric method to analyze the efficiency of $R \& D$ investment by considering the three factors of enterprise scale, market structure, the proportion of foreign investment and state-owned enterprises. Hecheng Wu (2008) constructed the input-output index system of R\&D efficiency, in which the input index is expressed by internal expenditure and development funds, and the output index is expressed by sales revenue. Liangqun Qi (2014) analyzed the impact of $R \& D$ personnel, $R \& D$ funds and the number of R\&D institutions in the subdivided industry on R\&D efficiency, which based on the panel data of equipment manufacturing industry from 2001 to 2010. Yong Jiao (2020) qualitatively analyzed the double squeeze situation in the process of technology paradigm evolution by constructing STP-G model, besides incremental innovation and disruptive innovation are the key to break the deadlock and promote the rise of GVC in manufacturing industry. 
Ruoen Ren (1998) used the multi-index method to measure the international competitiveness of the industry through three indicators: relative price level, productivity and cost. Xing Zhou (2000) established the evaluation index of industrial international competitiveness from four aspects, including industrial quality, current situation and development trend, environmental and institutional factors and internationalization degree. Hummels (2001) proposed that the international competitiveness of an industry can be measured by vertical specialization index. Bei Jin (2006) analyzed the industrial competitiveness of manufacturing industry from the perspective of comparative advantage and competitive advantage. The main measurement indexes are RCA index, Ms index, NTB index, etc. Tao Xu (2009) proposed that enterprise scale, economic openness and RMB exchange rate have little impact on international competitiveness. Based on the theory of added value, Zhang Yonghua (2013) measured the international competitiveness of manufacturing industry by using CA index and TC index.

In the existing research on R\&D investment, most of them are one-way or two-way causal analysis of R\&D investment and enterprise operation from the micro perspective. This paper analyzes the impact of R\&D investment structure on the development of equipment manufacturing industry in Hubei Province from the perspective of output. From the perspective of $R \& D$ investment, the proportion of $R \& D$ personnel, $R \& D$ investment efficiency and R\&D investment intensity are considered. In addition to $R \& D$ investment of the industry, the control variables such as FDI and enterprise scale are introduced to analyze the international competitiveness of equipment manufacturing industry.

\section{Theoretical analysis and hypothesis}

R\&D investment is an essential step for enterprises' independent innovation and industrial technological progress. At first, the increase of $R \& D$ investment will continuously stimulate $R \& D$ personnel to carry out active or passive innovation, so as to improve product quality and expand market power; secondly, the increase of $R \& D$ investment will improve labor quality and equipment efficiency, save unnecessary costs and promote the transformation and upgrading of manufacturing enterprises; ultimately, the increase of R\&D investment will drive the development of upstream and downstream industries and promote innovation. The positive externalities brought by integration and diffusion improve the technical level and production efficiency.

The structure of R\&D investment is analyzed from the perspective of industry. Although $R \& D$ investment can promote enterprise innovation, it should also consider the entire R\&D investment strength and $R \& D$ input-output efficiency of the industry. Then, the R\&D investment level and human cost are investigated from the micro perspective of the enterprise, considering that human resource is the most active factor in the production process, and as a technology carrier reflects the level of industrial technology, consequently it is particularly important to analyze the quantity and quality of labor force in the process of industrial development. Therefore, the hypothesis is put forward that the influencing factors of $\mathrm{R} \& \mathrm{D}$ investment are positively correlated with the international competitiveness of the industry.

In addition to considering the related indicators of R\&D investment, this paper introduces the control variables of FDI and enterprise size in the industry to analyze the international competitiveness of the computer and other electronic equipment manufacturing industry. The technology spillover effect brought by foreign investment has a significant positive impact on the total output growth of the industry, result in enhancing the international competitiveness; the free market theory tells us that the larger the scale of enterprises in the industry, the greater the market power and the higher the degree of industry concentration, the easier it is for manufacturers to have more capital and human resources than those in the free market, hence it is more conducive to R\&D promotion Technology upgrading and equipment updating of enterprises.

Most of the existing analysis on the international competitiveness of industry is conducted from the perspective of input-output. From the perspective of input, Michael Porter diamond Model system and its evolution GEM model are widely used; from the perspective of output, there are many kinds of measurement indicators: international market share (MS), dominant comparative advantage index (RCA), trade competitiveness index (TC), comparable net export index (NTB), etc.

\section{Data processing and index analysis}

Through the data collection and processing of China Industrial statistical yearbook, China Science and technology statistical yearbook and Hubei Province Yearbook, this paper analyzes the manufacturing industry segmentation, and calculates the international competitiveness index of manufacturing industry segmentation. The indicators used in this paper are as follows: the competitiveness of manufacturing industry, the proportion of $R \& D$ personnel, $R \& D$ investment intensity, R\&D input-output efficiency, and the introduction of FDI and industry size two control variables. Data selection from 1990 to 2019 Hubei communication equipment and computer and other electronic equipment manufacturing industry related data. The RCA index is used to measure the international competitiveness of industries. The higher the proportion is, the more important the sub industries are among the 31 manufacturing industries. The proportion of $\mathrm{R} \& \mathrm{D}$ personnel is Hum. The higher the value is, the more attention the industry attaches to the R\&D of new products; the R\&D investment intensity is expressed by the ratio of $R \& D$ expenditure of enterprises in the industry to the total output value of the industry; the higher the value is, the more the enterprises spend on technological innovation; the R\&D input-output 
efficiency is expressed by the proportion of sales revenue of new products to the operating revenue of enterprises in the industry; the control variable foreign investment FDI is expressed by the ratio of the foreign capital of the enterprise in the industry to the owner's equity of the enterprise. The control variable industry scale is expressed by the ratio of the total output value of each industry to that of all manufacturing industries.

\section{Construction and analysis of econometric model}

From the National Bureau of statistics and Hubei
Provincial Bureau of statistics, this paper collects the data of trade in goods and services of communication equipment, computer and other electronic equipment manufacturing industry over the years, and analyzes the current situation of trade by calculating the index of international competitiveness of the industry - the dominant comparative advantage index (RCA).

Firstly, the stationarity of each time series data is tested, and the method used in this paper is ADF test. According to the results of ADF test (Table 1), RCA, hum, inten, eff, FDI and scale are all first-order single integral series.

Table 1. ADF test results

\begin{tabular}{|c|c|c|c|c|c|c|c|}
\hline sequence & $\begin{array}{l}\text { ADF } \\
\text { statistics }\end{array}$ & $\begin{array}{l}0.05 \\
\text { Critical } \\
\text { Value }\end{array}$ & conclusion & $\begin{array}{l}1^{\text {st }} \text { difference } \\
\text { sequence }\end{array}$ & $\begin{array}{l}\text { ADF } \\
\text { statistics }\end{array}$ & $\begin{array}{l}0.05 \\
\text { Critical } \\
\text { Value }\end{array}$ & conclusion \\
\hline rea & -1.236634 & -1.95291 & unstationarity & $\Delta \mathrm{rca}$ & -5.302912 & -2.971853 & stationarity \\
\hline hum & -3.188593 & -3.574244 & unstationarity & $\Delta$ hum & -4.864773 & -1.95502 & stationarity \\
\hline inten & -2.811787 & -3.574244 & unstationarity & $\Delta$ inten & -5.804872 & -1.953381 & stationarity \\
\hline eff & -3.514136 & -3.612199 & unstationarity & $\Delta \mathrm{eff}$ & -4.521426 & -3.644963 & stationarity \\
\hline scale & -2.453338 & -3.574244 & unstationarity & $\Delta$ scale & -7.474812 & -2.971853 & stationarity \\
\hline fdi & 1.42776 & -1.95291 & unstationarity & $\Delta$ fdi & -6.823774 & -2.971853 & stationarity \\
\hline
\end{tabular}

Secondly, the VAR model is established, and the optimal lag order of the model is determined as the third order. Johansen cointegration test was performed on the variables, and the test results are as follows (Table 2). It shows that there is a long-term equilibrium relationship among RCA, hum, inten, eff, FDI and scale. The following error correction model is established:

$D R C A=2.9501 * D H U M+21.3727 *$ DINTEN $-0.0189 * D E F F+25.8199 *$ DSCALE

$$
+2.7151 * D F D I-0.4509 * E C M(-1)-0.1073
$$

The parameters indicate that the previous value of R\&D investment and the previous value of industry scale have a significant impact on the international competitiveness of the industry, and the coefficient of error term is -0.45086719473 , which indicates that the long-term equilibrium relationship has a greater adjustment to the short-term volatility.

Table 2. Johansen test results

\begin{tabular}{lllll}
\hline Hypothesized & & Trace & 0.05 & \\
No. of CE(s) & Eigenvalue & Statistic & Critical Value & Prob.** \\
\hline None * & 0.739296 & 113.1304 & 95.75366 & 0.0019 \\
At most 1 & 0.684928 & 75.48802 & 69.81889 & 0.0164 \\
At most 2 & 0.572721 & 43.14933 & 47.85613 & 0.1290 \\
At most 3 & 0.392520 & 19.34045 & 29.79707 & 0.4686 \\
At most 4 & 0.126473 & 5.384250 & 15.49471 & 0.7667 \\
At most 5 & 0.055480 & 1.598190 & 3.841466 & 0.2062 \\
\hline
\end{tabular}

Finally, the Granger causality test is carried out. Only one pair of variables (eff \& inten) rejected the hypothesis that there is no Granger causality in the test with lag period of 3 , indicating that there is a short-term bidirectional causality between $R \& D$ investment efficiency and R\&D investment intensity.

\section{Conclusion}

Among the three variables of $R \& D$ investment structure, R\&D personnel proportion has a smaller effect on the industrial competitiveness of communication equipment industry; the most vital factor affecting the international competitiveness of the industry is R\&D investment, and the increase of R\&D investment promotes the improvement of the international competitiveness of the industry; while the R\&D investment efficiency has a weak inverse relationship with the international competitiveness of the industry, which may be due to the following reasons China's manufacturing industry is in the stage of transformation and upgrading. At this time, the $R \& D$ investment of new products is more, and the increase of output value brought by new products lags behind the investment. China's manufacturing industry is now in the state of "low-end lock-in". At the same time, western countries also adopt various kinds of technology blockade. In order to break the deadlock, only by actively training and introducing R\&D personnel, 
increasing independent R\&D efforts, accelerating technological transformation and shortening product R\& $\mathrm{D}$ cycle, can we optimize the industrial structure of manufacturing industry and promote the upgrading of industrial structure.

\section{Acknowledgments}

Project: Research on the impact of R\&D investment on innovation development cycle of small and medium-sized science and technology enterprises in Hubei Province (No. HBSME2019A01)

\section{References}

1. Yi KeiMu. The Nature and Growth of Vertical Specialization in World Trade 1999 J. Social Science Electronic Publishing, 154

2. Pan Wenqing. The spillover effect of foreign investment on China's industrial sector: an analysis based on Panel Data 2003 J. World economy, 0637

3. Jin Bei, Li Gang, Chen Zhi. An empirical analysis on the international competitiveness of China's manufacturing industry since China's entry into WTO 2006 J. China's industrial economy, 10514

4. Zhu Youwei, Xu Kangning. Empirical research on R\&D efficiency of China's hightech industry $2006 \mathrm{~J}$. China's industrial economy, 11 38-45

5. Yu Zipeng, Wang Jinchao. Financial development, R\&D investment and international competitiveness of hightech industry 2018 J. Hubei Social Sciences, 11 51-58

6. Wei Qingwen, Yang Huixin, Wang Jun. the mechanism of innovation driven on the evolution of the new system of modern industrial development from the perspective of production function $2018 \mathrm{~J}$. Modern finance and Economics, 07 103-113

7. Yu Zipeng, Yuan Lingli. Factor quality, business environment and international competitiveness of China's manufacturing industry 2019 J. Economy and management,33 54-60

8. Duan Minfang, Zuo Shuang. Comparative study on international competitiveness of China's manufacturing industry 2019 J. Journal of Central South University for Nationalities,39 107-111 